\title{
Activated Carbon Adsorption of Fuel Oxygenates MTBE and ETBE from Water
}

\author{
Fikret Inal • Senem Yetgin • Gulsum T. Aksu • \\ Selvi Simsek • Aysun Sofuoglu • Sait C. Sofuoglu
}

Received: 14 November 2008 / Accepted: 25 February 2009 / Published online: 17 March 2009

(C) Springer Science + Business Media B.V. 2009

\begin{abstract}
The aqueous phase adsorption of fuel oxygenates methyl tertiary butyl ether (MTBE) and ethyl tertiary butyl ether (ETBE) onto commercially available granular activated carbon (GAC; Norit GAC 1240) was investigated in a batch system at $27^{\circ} \mathrm{C}$. The oxygenate concentrations were determined by headspace gas chromatography/mass spectrometry analyses. The experimental data were used with four two-parameter isotherm models (Langmuir, Freundlich, Temkin, and DubininRadushkevich) and two kinetic models (pseudo firstorder and pseudo second-order) to determine equilibrium and kinetic parameters. Considering the correlation coefficient and root mean square error, Dubinin-Radushkevich isotherm showed better fit with the equilibrium data for MTBE. However, the performances of Langmuir and Dubinin-Radushkevich models were comparable for ETBE. The adsorption capacities were calculated as 5.50 and $6.92 \mathrm{mg} / \mathrm{g}$ for MTBE and ETBE, respectively, at an equilibrium solution concentration of $1 \mathrm{mg} / \mathrm{L}$ using Dubinin-Radushkevich isotherm. The differences between the model predictions and experimental data were similar for the pseudo first-order and pseudo secondorder kinetic models. Gibbs free-energy changes of
\end{abstract}

F. Inal $(\bowtie) \cdot S$. Yetgin $\cdot$ G. T. Aksu $\cdot$ S. Simsek •

A. Sofuoglu $\cdot$ S. C. Sofuoglu

Department of Chemical Engineering,

Izmir Institute of Technology,

Gulbahce-Urla,

35430 Izmir, Turkey

e-mail: fikretinal@iyte.edu.tr adsorption were found to be -22.59 and $-28.55 \mathrm{~kJ} / \mathrm{mol}$ for MTBE-GAC and ETBE-GAC systems, respectively, under the experimental conditions studied.

Keywords Adsorption · Fuel oxygenate - MTBE . ETBE

\section{Introduction}

Oxygen-containing compounds (i.e., oxygenates) were first used as octane enhancer in gasoline in late 1970s. The phase-out of lead-including additives due to their toxic properties increased the consumption of oxygenates in gasoline. The addition of oxygenate into gasoline also reduced the toxic emissions from motor vehicles. Therefore, in the USA, oxygenated fuel and reformulated gasoline were required in $\mathrm{CO}$ and ozone non-attainment areas, respectively in Clean Air Act Amendments of 1990. There are two main groups of compounds that can be considered as fuel oxygenates: alcohols (e.g., methanol and ethanol) and ethers (e.g., methyl tertiary butyl ether (MTBE), ethyl tertiary butyl ether (ETBE), and tertiary amyl methyl ether (TAME)). Ethers have low heat of vaporization and can be blended at the refinery. They are not as sensitive to water as the alcohols and can be transported efficiently to the marketplace using the current gasoline distribution systems. Therefore, ether oxygenates have been preferred by the refiners. MTBE is the most common fuel oxygenate used worldwide. 
ETBE is mostly used in Europe (e.g., France, Italy, and Spain). The consumption of ETBE is expected to increase due to tax incentives for the use of ethanol in its production since ethanol can be obtained from renewable sources.

The widespread introduction of oxygenates, especially MTBE, into fuel systems has increased the incidence of surface water and groundwater contaminations. Water contamination can occur mainly from leaking aboveground and underground fuel storage tanks, pipelines, and refueling spills. Additionally, watercraft activities can also cause contaminations in harbors, lakes, and open water reservoirs. With respect to other gasoline constituents (e.g., benzene, toluene, ethylbenzene, and xylenes (BTEX)) MTBE has a relatively high solubility in water $(43-54 \mathrm{~g} / \mathrm{L})$ and little affinity for soil $\left(\log K_{\mathrm{oc}}=1.0-1.1(\log \mathrm{L} / \mathrm{kg})\right.$; API, 2000). Consequently, it moves rapidly from leaking fuel storage tanks or point of spill through the soil to an aquifer. ETBE has lower water solubility $(26 \mathrm{~g} / \mathrm{L})$ and higher partition coefficient $\left(\log K_{\mathrm{oc}}=\right.$ 1.0-2.2 $(\log \mathrm{L} / \mathrm{kg}))$ compared to MTBE.

Ethers affect the esthetic quality of drinking water since they have unpleasant taste and odor. MTBE can be detected at $2.5 \mu \mathrm{g} / \mathrm{L}$ for odor and $2.0 \mu \mathrm{g} / \mathrm{L}$ for taste (US EPA 2000). For that reason, public water systems are required to monitor MTBE contamination by the local or federal authorities in many regions. The US Environmental Protection Agency (EPA) classified MTBE as a possible human carcinogen on the basis of inhalation cancer tests (US EPA 2000). Recently, Finish Environment Institute has also prepared riskassessment report for MTBE on behalf of the European Commission (EC 2002).

Trihalomethanes, solvents, and gasoline oxygenates were the most commonly detected volatile organic compounds in ambient groundwater sampled by the National Water-Quality Assessment Program of the US Geological Survey (USGS; USGS 2001). MTBE was detected in about 5\% of groundwater samples collected across the USA with concentrations typically well below the EPA drinking water consumer advisory concentrations of 20 to $40 \mu \mathrm{g} / \mathrm{L}$ (US EPA 1997). Only less than $1 \%$ of samples exceeded $20 \mu \mathrm{g} / \mathrm{L}$. The USGS study also indicated that MTBE was most frequently detected in groundwater underlying urban areas in comparison to agricultural and mixed land-use settings. In a joint study of USGS and EPA, data on finished drinking water from selected communities in
12 states in the USA were examined (USGS 2001). MTBE was detected in $9 \%$ of the community water systems. The concentrations were low, and less than $1 \%$ exceeded the EPA consumer advisory concentration, a finding which is consistent with the USGS study of ambient groundwater. MTBE concentrations measured in river water and drinking water in Germany have been reported to be approximately two to three orders of magnitude lower than the US drinking water standard of 20-40 $\mu \mathrm{g} / \mathrm{L}$ (Achten et al. 2002). In Spain, a monitoring program was carried out to determine MTBE, its main degradation products, and other gasoline additives in 21 groundwater wells that were located near different gasoline point sources (Rosell et al. 2003). All samples contained MTBE at levels ranging from 0.3 to $70 \mu \mathrm{g} / \mathrm{L}$ (with a maximum concentration of $670 \mu \mathrm{g} / \mathrm{L}$ in one site). ETBE was detected below $1 \mu \mathrm{g} / \mathrm{L}$.

The removal of ether contaminants from water has been studied extensively in the literature. The most of these studies focused on MTBE remediation since it is the main fuel oxygenate used. The effectiveness of several water treatment processes has been considered such as catalytic conversion (Centi et al. 2002), membrane separation (Urkiaga et al. 2002), biodegradation (Steffan et al. 1997), air stripping (Wilhelm et al. 2002; Sutherland et al. 2004; Sutherland et al. 2005), advanced oxidation $\left(\mathrm{O}_{3} / \mathrm{H}_{2} \mathrm{O}_{2}\right.$ and $\mathrm{UV} / \mathrm{H}_{2} \mathrm{O}_{2}$; Sutherland et al. 2004; Sutherland et al. 2005), and adsorption (Wilhelm et al. 2002; Sutherland et al. 2004; Sutherland et al. 2005). Adsorption is one of the most utilized and effective processes for the removal of volatile organic compounds from water. Different adsorbents have been tested for the ether oxygenates: zeolites (Anderson 2000; Li et al. 2003; Erdem-Senatalar et al. 2004), resins (Annesini et al. 2000; Davis and Powers 2000; Lin et al. 2002; Bi et al. 2005; Hung and Lin 2006), and activated carbon (granular, powdered, or activated carbon fiber; Sutherland et al. 2004; Sutherland et al. 2005; Davis and Powers 2000; Li et al. 2002; Shih et al. 2003; Yu et al. 2005; Quinlivan et al. 2005).

Batch adsorption experiments were carried out to screen the alternative sorbents (synthetic carbonaceous resins, porous graphitic carbon, acrylic resins, octadecyl (C18) silicas, and bituminous coal granular activated carbon (GAC; Calgon F400)) for treating groundwater contaminated with MTBE (Davis and Powers 2000). The results showed that porous graphitic carbon and two synthetic carbonaceous 
resins had a greater capacity for MTBE than activated carbon.

$\mathrm{Yu}$ et al. (2005) have obtained isotherms for the adsorption of MTBE and other fuel oxygenates (ETBE, TAME, diisopropyl ether (DIPE), tert-butyl alcohol (TBA), and ethanol (EtOH)) on two bituminous coal activated carbons (Calgon F400 and F600). The relative capacities of adsorbents were DIPE $>$ TAME $>$ ETBE $>$ MTBE $>$ TBA, EtOH.

The performances of two coconut shell GACs in removing MTBE in the presence of competitors (natural organic matter, TBA, and BTX) have been evaluated using rapid small-scale column tests (Shih et al. 2003).

The majority of the adsorption studies in the literature are on the removal of MTBE from water. However, the consumption of ETBE as a fuel oxygenate is expected to increase due to the phaseout of MTBE in some countries. There are few studies on equilibrium and kinetics of ether oxygenate adsorption. Our objective in this study was to investigate equilibrium and kinetics of MTBE and ETBE adsorption onto GAC and calculate Gibbs freeenergy change of adsorption. The adsorbent selected (i.e., NORIT GAC 1240) was steam-activated coal GAC. It was recommended for the superior adsorption properties for compounds causing taste and odor problems in water.

\section{Materials and Methods}

MTBE (99.8\%) and ETBE (99\%) were obtained from LabScan and Aldrich, respectively. Sodium chloride (99.5\%, Panreac) was used to increase the extraction efficiency in headspace analysis. The adsorbent (NORIT GAC 1240) was purchased from Fluka. Some of the manufacturer-provided properties of GAC are given in Table 1. Adsorbent was dried at $110^{\circ} \mathrm{C}$ for $4 \mathrm{~h}$ and stored in a desiccator before being used in the experiments.

All the solutions were prepared with deionized water obtained from Milli-Q Ultrapure Water Purification system. The concentrations of MTBE and ETBE in stock solutions were $2,000 \mathrm{mg} / \mathrm{L}$. Standard oxygenate solutions were made from these stock solutions. Batch equilibrium and kinetic experiments were carried out in headspace-free $40 \mathrm{ml}$ vials with polytetrafluorethylene (PTFE)-faced silicon septum
Table 1 Properties of adsorbent (Norit GAC 1240)

\begin{tabular}{lll}
\hline & GAC & Units \\
\hline Iodine number & 1075 & - \\
Methylene blue adsorption & 22 & $\mathrm{~g} / 100 \mathrm{~g}$ \\
Total surface area (BET) & 1,175 & $\mathrm{~m}^{2} / \mathrm{g}$ \\
Apparent density & 480 & $\mathrm{~kg} / \mathrm{m}^{3}$ \\
Effective size & $0.6-0.7$ & $\mathrm{~mm}$ \\
Ash content & 7 & mass $\%$ \\
\hline
\end{tabular}

(EPA Vial, Cole-Parmer). The solid/liquid ratio was constant for all the samples at $8 \mathrm{~g} / \mathrm{L}$, which was decided after preliminary tests. Since MTBE concentrations up to $80 \mathrm{mg} / \mathrm{L}$ have been reported in groundwater in the vicinity of gasoline-contaminated sites (Schirmer et al. 2002), initial oxygenate concentrations $\left(C_{0}\right)$ were in the range of $1-50 \mathrm{mg} / \mathrm{L}$ in adsorption isotherm experiments. Samples were equilibrated in a shaking water-bath (GFL 1086) with microprocessor-controlled temperature regulation (temperature constancy: $\pm 0.1^{\circ} \mathrm{C}$ ) at $27^{\circ} \mathrm{C}$ and shaking frequency of $100 \mathrm{rpm}$ for $48 \mathrm{~h}$. Preliminary tests have also indicated that the time to reach the equilibrium was less than $48 \mathrm{~h}$ for both MTBE and ETBE. In kinetic experiments, samples were taken periodically for the determination of aqueous-phase oxygenate concentrations. Three different initial oxygenate concentrations (i.e., $C_{0}=2,5$, and $15 \mathrm{mg} / \mathrm{L}$ ) were studied in these tests. Ten milliliters of supernatant in the vial was transferred with a gas-tight syringe equipped with PTFE filter (PTFE Membrane 25/45, Agilent) to $20 \mathrm{ml}$ headspace vial containing $2 \mathrm{~g} \mathrm{NaCl}$ for the sample quantification. Blank vials (containing only deionized water) and control vials (containing standard oxygenate solutions of known concentration) were also used for each set of isotherm and kinetic experiments. The analyses of control vials confirmed that there were no significant losses of oxygenates due to volatilization during the experiments.

Gas chromatography (GC) has been used mainly with different detectors (e.g., photoionization detector, flame ionization detector, mass selective detector) for the analyses of ether oxygenates in water. GC/MS is a more reliable and sensitive technique. A variety of sample preparation or enrichment methods can be coupled to GC/MS such as direct aqueous injection (Church et al. 1997; Hong et al. 1999; Zwank et al. 
2002), headspace (Lin et al. 2003), solid phase microextraction (Piazza et al. 2001; Dewsbury et al. 2003), and purge and trap (Rosell et al. 2003). The selection of the analysis technique depends on the desired selectivity, sensitivity, and matrix to be analyzed.

Quantitative analyses were performed using a static headspace-gas chromatography/mass spectrometry system (HS-GC/MS; HS: Agilent 7694 Headspace Sampler, GC: Agilent 6890, MS: Agilent 5973) equipped with a capillary column (HP-5MS, $30 \mathrm{~m} \times$ $0.25 \mathrm{~mm} \times 0.25 \mu \mathrm{m})$. Samples were heated in the headspace oven at $80^{\circ} \mathrm{C}$ for $20 \mathrm{~min}$. Headspace vial was then pressurized with helium for $1.0 \mathrm{~min}$. Sample was transferred to the injection port of GC through the heated transfer line kept at $180^{\circ} \mathrm{C}$. The GC injection port temperature was $200^{\circ} \mathrm{C}$. The split ratio was $1: 13$. Carrier gas was helium with a flow rate of $1.0 \mathrm{ml} / \mathrm{min}$. The column head pressure was maintained at 6.78 psi. The oven temperatures were $35^{\circ} \mathrm{C}$ initial for $1 \mathrm{~min}$ and $20^{\circ} \mathrm{C} / \mathrm{min}$ ramp to $250^{\circ} \mathrm{C}$. Selected ion monitoring mode was used for the detection and quantification of MTBE and ETBE with the following selected ions; MTBE: 73, 57 ETBE: 59, 87. MS source and quadruple temperatures were $230^{\circ} \mathrm{C}$ and $150^{\circ} \mathrm{C}$, respectively. Five-point calibrations were performed for the determination of concentrations of oxygenates. The correlation coefficients $\left(R^{2}\right)$ for the calibration curves were 0.989 and 0.987 for MTBE and ETBE, respectively. Instrumental MTBE and ETBE detection limits were $0.1 \mu \mathrm{g} / \mathrm{L}$ (based on the signal/noise $=3$ ). Some of the isotherm experiments were completed twice to check the repeatability. It was found that data were repeatable (mean \pm standard deviation= $9.8 \pm 6.4 \%)$.

\section{Results and Discussion}

The experimental data were analyzed by equilibrium and kinetic models. Four two-parameter isotherm models (Langmuir, Freundlich, Temkin, and Dubinin-Radushkevich (D-R)) and two kinetic models (pseudo first-order and pseudo second-order) were tested.

The amount of oxygenate adsorbed per unit adsorbent mass was calculated by a simple mass balance:

$q=\left(C_{0}-C_{t}\right) \frac{V}{m}$ where $q$ is the amount adsorbed $(\mathrm{mg} / \mathrm{g}), C_{0}$ is the initial oxygenate concentration $(\mathrm{mg} / \mathrm{L}), C_{t}$ is the concentration at time $t(\mathrm{mg} / \mathrm{L}), V$ is the solution volume $(\mathrm{L})$, and $m$ is the mass of the adsorbent (g).

Batch equilibrium and kinetic parameters were obtained using nonlinear regression analysis (POLYMATH 5.1). Two indicators were used to compare various models representing the same dependent variable (i.e., $q_{\mathrm{e}}$ for the isotherm models and $q$ for the kinetic models): correlation coefficient $\left(R^{2}\right)$ and root mean square error (RMSE; or root mean square deviation). The correlation coefficient is frequently used to decide whether the model represents correctly the experimental data. RMSE is defined as;

RMSE $=\sqrt{\frac{\sum_{1}^{N}\left(q_{\text {exp }}-q_{\text {model }}\right)^{2}}{N}}$

where $q_{\text {exp }}$ and $q_{\text {model }}$ are the experimentally measured and model prediction for the amount of oxygenate adsorbed, respectively. A model with smaller RMSE represents the data more accurately than a model with larger values of this indicator.

The single-solute equilibrium data and isotherm model predictions are given in Fig. 1 for MTBE and Fig. 2 for ETBE. In figures, symbols represent experimental data, and lines represent model predictions. The isotherm parameters obtained by nonlinear regression analysis are provided in Table 2. Brief information about the isotherm model equations used is given below.

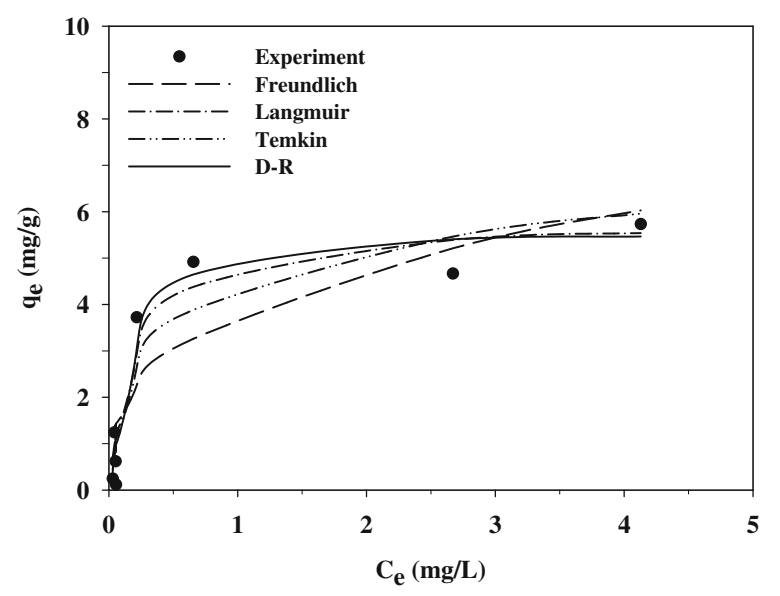

Fig. 1 Experimental equilibrium data and adsorption isotherms for MTBE 


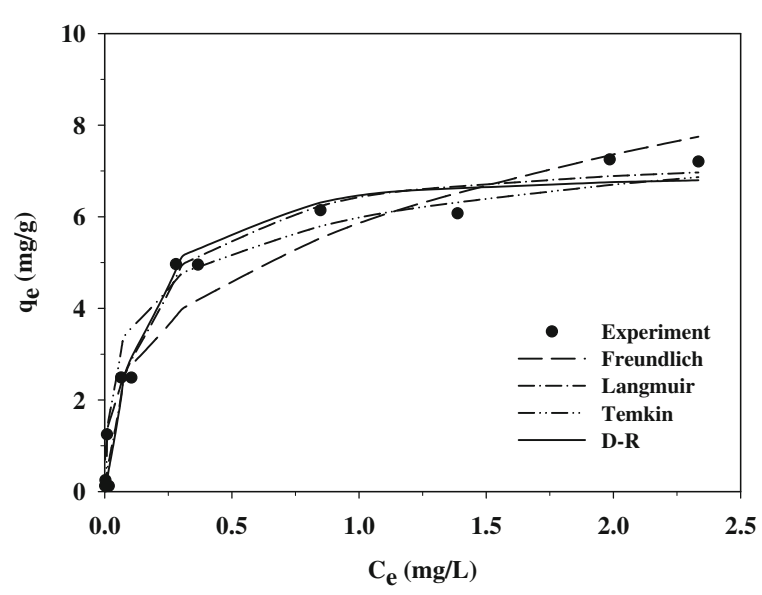

Fig. 2 Experimental equilibrium data and adsorption isotherms for ETBE

\subsection{Freundlich Isotherm}

$q_{e}=K_{f} C_{e}^{1 / n}$

where $K_{f}$ and $n$ are Freundlich constants and related to the adsorption capacity and adsorption intensity, respectively. Since $1<n<10$ for both oxygenates $(n=$ 2.994 for MTBE and $n=3.005$ for ETBE), adsorption onto GAC is favorable (Gunay et al. 2007). However, for MTBE, low correlation coefficient $\left(R^{2}=0.778\right)$ and high RMSE (RMSE $=1.029)$ were obtained with this model. Yu et al. (2005) have also reported $n$ values for two GACs as 1.479 and 1.608 (GAC: Calgon F400) and 1.414 and 2.028 (GAC: Calgon F600) for MTBE and ETBE, respectively.

\subsection{Langmuir Isotherm}

$q_{e}=\frac{K_{\mathrm{L}} a_{\mathrm{L}} \mathrm{C}_{\mathrm{e}}}{1+a_{\mathrm{L}} \mathrm{C}_{\mathrm{e}}}$

where $K_{\mathrm{L}}$ and $a_{\mathrm{L}}$ are Langmuir parameters related to the adsorption capacity and energy of adsorption, respectively. The ratio of $K_{\mathrm{L}} / a_{\mathrm{L}}$ is the maximum amount of oxygenate adsorbed per unit mass of adsorbent $\left(q_{\max }\right)$ to form a complete monolayer. The maximum monolayer adsorption capacities were found to be similar for both oxygenates $(1.266 \mathrm{mg} / \mathrm{g}$ for MTBE and $1.252 \mathrm{mg} / \mathrm{g}$ for ETBE). These $q_{\max }$ values are comparable with those reported in the literature for different GACs. Yu et al. (2005) have reported $q_{\max }$ for the adsorption of MTBE and ETBE onto Calgon F400 and F600. $q_{\max }$ was 0.686 and $1.799 \mathrm{mg} / \mathrm{g}$ when the adsorbent was F400 and 1.434 and $1.849 \mathrm{mg} / \mathrm{g}$ when the adsorbent was F600 for MTBE and ETBE, respectively.

The separation factor $\left(R_{\mathrm{L}}\right)$ is used for Langmuir isotherm to decide whether the adsorption process is favorable or unfavorable (Gunay et al. 2007). It is a dimensionless constant and defined as:

$R_{\mathrm{L}}=\frac{1}{\left(1+a_{\mathrm{L}} C_{0}\right)}$

Depending on the initial oxygenate concentrations, $R_{\mathrm{L}}$ values were found to be in the range of 0.004 0.178 and $0.003-0.144$ for MTBE and ETBE, respectively, which indicate favorable adsorption.

\subsection{Temkin Isotherm}

$q_{e}=\frac{R T}{b} \ln \left(K_{\mathrm{Te}} C_{e}\right)$

where $K_{\mathrm{Te}}$ is Temkin isotherm constant $(\mathrm{L} / \mathrm{g}), b$ is related to heat of adsorption $(\mathrm{J} / \mathrm{mol}), R$ is the gas constant $\left(8.314 \times 10^{-3} \mathrm{~kJ} / \mathrm{K} \mathrm{mol}\right)$, and $T$ is the absolute temperature (K). Temkin model constants $K_{\mathrm{Te}}$ and $b$

Table 2 Adsorption isotherm parameters

\begin{tabular}{|c|c|c|c|}
\hline & & MTBE & ETBE \\
\hline \multirow[t]{4}{*}{ Freundlich } & $K_{f}$ & 3.753 & 5.844 \\
\hline & $n$ & 2.994 & 3.005 \\
\hline & $R^{2}$ & 0.778 & 0.937 \\
\hline & RMSE & 1.029 & 0.668 \\
\hline \multirow[t]{4}{*}{ Langmuir } & $K_{\mathrm{L}}$ & 5.829 & 7.468 \\
\hline & $a_{\mathrm{L}}$ & 4.605 & 5.962 \\
\hline & $R^{2}$ & 0.916 & 0.977 \\
\hline & RMSE & 0.634 & 0.410 \\
\hline \multirow[t]{4}{*}{ Temkin } & $b$ & 221.299 & 235.122 \\
\hline & $K_{\mathrm{Te}}$ & 47.750 & 276.934 \\
\hline & $R^{2}$ & 0.887 & 0.936 \\
\hline & RMSE & 0.733 & 0.651 \\
\hline \multirow[t]{4}{*}{ Dubinin-Radushkevich } & $q_{\mathrm{m}}$ & 5.516 & 6.933 \\
\hline & $E$ & 24.980 & 28.316 \\
\hline & $R^{2}$ & 0.940 & 0.971 \\
\hline & RMSE & 0.536 & 0.457 \\
\hline
\end{tabular}


were determined as $47.750 \mathrm{~L} / \mathrm{g}$ and $221.299 \mathrm{~J} / \mathrm{mol}$ for MTBE, and 276.934 L/g and 235.122 J/mol for ETBE, respectively. High RMSE $(\mathrm{RMSE}=0.733)$ and low correlation coefficient $\left(R^{2}=0.887\right)$ were obtained for MTBE when Temkin isotherm was tested.

\subsection{Dubinin-Radushkevich Isotherm}

$q_{e}=q_{\mathrm{m}} \exp \left(\frac{\left(R T \ln \left(1+1 / C_{e}\right)\right)^{2}}{-2 E^{2}}\right)$

where $q_{\mathrm{m}}$ is the maximum adsorption capacity $(\mathrm{mg} / \mathrm{g})$, and $E$ is the energy of adsorption $(\mathrm{kJ} / \mathrm{mol})$. The constants $q_{\mathrm{m}}$ and $E$ were found to be $5.516 \mathrm{mg} / \mathrm{g}$ and $24.980 \mathrm{~kJ} / \mathrm{mol}$ for MTBE and $6.933 \mathrm{mg} / \mathrm{g}$ and $28.316 \mathrm{~kJ} / \mathrm{mol}$ for ETBE, respectively. The $q_{\mathrm{m}}$ values were higher than those obtained from the Langmuir equation. It has been reported that $E$ values lower than $83 \mathrm{~kJ} / \mathrm{mol}$ confirms the physical nature of the adsorption (Gimeno et al. 2003).

$R^{2}$ and RMSE values were similar for the Langmuir and D-R models for ETBE (Table 2). However, relatively higher correlation coefficient $\left(R^{2}\right.$ of 0.940$)$ and lower error (RMSE of 0.536 ) were obtained with D-R model compared to other isotherms used for MTBE. Therefore, the amount of oxygenate adsorbed at $C_{\mathrm{e}}=1 \mathrm{mg} / \mathrm{L}$ was calculated using D-R model and found to be 5.50 and $6.92 \mathrm{mg} / \mathrm{g}$ for MTBE and ETBE, respectively. GAC used in the experiments showed greater affinity to ETBE than MTBE since ETBE has lower solubility in water. Similar result was also obtained with different GACs (Yu et al. 2005). Davis and Powers (2000) have reported sorption capacity of Calgon F400 as $3.1 \mathrm{mg} / \mathrm{g}$ at $C_{\mathrm{e}}=1 \mathrm{mg} / \mathrm{L}$ for MTBE. The sorption capacities higher than those reported here were stated for carbonaceous resins (Ambersorb 563, Ambersorb 572; Davis and Powers 2000; Bi et al. 2005), mordenite (Anderson 2000), and all-silica $\beta$ zeolite ( $\mathrm{Li}$ et al. 2003).

\subsection{Adsorption Kinetics}

To investigate adsorption kinetics, pseudo first-order and pseudo second-order models were tested with experimental adsorption capacity $(q)$ versus time $(t)$ data. In pseudo first-order kinetic equation, adsorption capacity is given as:

$q_{t}=q_{\mathrm{e}}\left(1-\exp \left(-k_{1} t\right)\right)$ where; $q_{t}$ is the adsorption capacity at time $t, q_{\mathrm{e}}$ is the adsorption capacity at equilibrium, and $k_{1}\left(\mathrm{~h}^{-1}\right)$ is the first-order rate constant. $q_{\mathrm{e}}$ and $k_{1}$ were determined by nonlinear regression.

The pseudo second-order kinetic model can be expressed as;

$q_{t}=\frac{q_{\mathrm{e}}^{2} k_{2} t}{1+q_{\mathrm{e}} k_{2} t}$

where $k_{2}(\mathrm{~g} / \mathrm{mg} \mathrm{h})$ is the pseudo second-order rate constant and was calculated by nonlinear regression analysis.

The experimental adsorption capacity versus time data and model predictions are given in Figs. 3 and 4 for MTBE and ETBE, respectively. The model parameter values are presented in Table 3. The experimental $q_{\mathrm{e}}$ values were also included in Table 3 to compare with those predicted. As can be seen from Figs. 3 and 4, the amount of MTBE and ETBE adsorbed increased with time until the equilibrium was reached. The maximum adsorption capacity was obtained at about $15 \mathrm{~h}$ for MTBE and $20 \mathrm{~h}$ for ETBE with the exception of $C_{0}=15 \mathrm{mg} / \mathrm{L}$ ETBE data. When the initial ETBE concentration was $15 \mathrm{mg} / \mathrm{L}$, it took about $30 \mathrm{~h}$ to reach the equilibrium. An increase in initial oxygenate concentration from 2 to $15 \mathrm{mg} / \mathrm{L}$ increased the amount of oxygenate adsorbed both for MTBE and ETBE. The performances of kinetic models tested were comparable based on the correlation coefficients and RMSEs for each oxygenate. The highest RMSE ( 0.174 and 0.178 for pseudo first-order

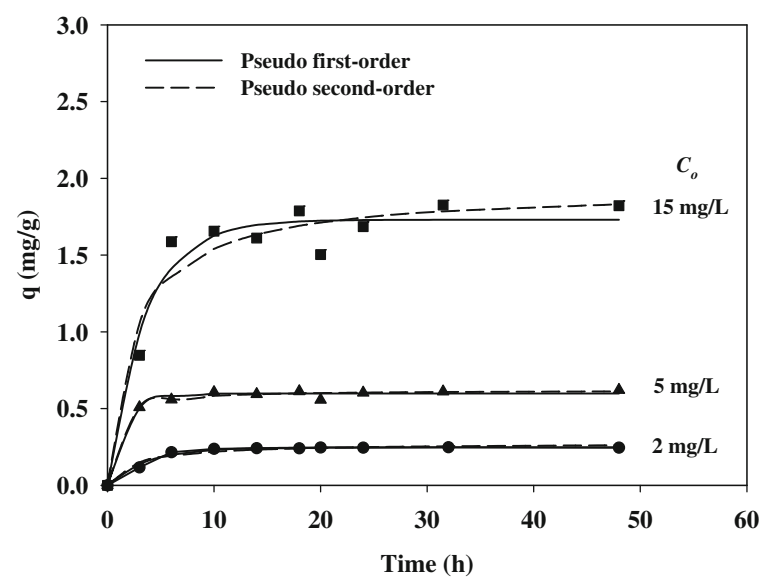

Fig. 3 Comparison of pseudo first-order and pseudo secondorder kinetic models with experimental data for MTBE adsorption 


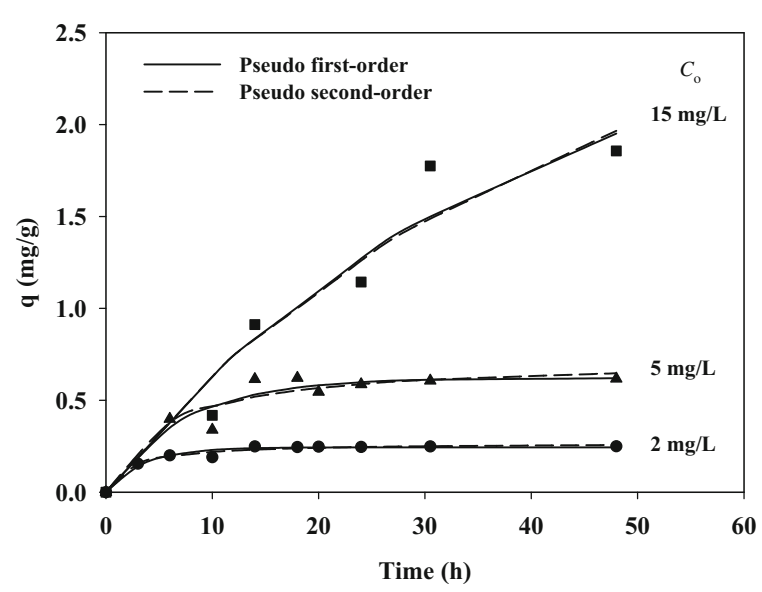

Fig. 4 Comparison of pseudo first-order and pseudo secondorder kinetic models with experimental data for ETBE adsorption

and pseudo second-order models, respectively) were obtained for ETBE at $C_{0}=15 \mathrm{mg} / \mathrm{L}$.

\subsection{Gibbs Free-Energy Change of Adsorption}

The Gibbs free-energy change $(\Delta G)$ of adsorption was calculated from the following equation (Milonjic, 2007):

$\Delta G=-R T \ln 10^{3} \mathrm{~K}$

where $K$ is the equilibrium constant. Since the value of $K$ obtained from Khan and Singh plot $\left(\left(\ln \left(q_{\mathrm{e}} / C_{\mathrm{e}}\right)\right.\right.$ versus $q_{\mathrm{e}}$; Fig. 5) has a unit of $\left(\mathrm{g} \mathrm{g}^{-1}\right), K$ was recalculated as dimensionless by multiplying it with $10^{3}$ to have a correct value of $\Delta G$. The Gibbs freeenergy changes were determined as $-22.59 \mathrm{~kJ} / \mathrm{mol}$ for MTBE and $-28.55 \mathrm{~kJ} / \mathrm{mol}$ for ETBE at $27^{\circ} \mathrm{C}$.

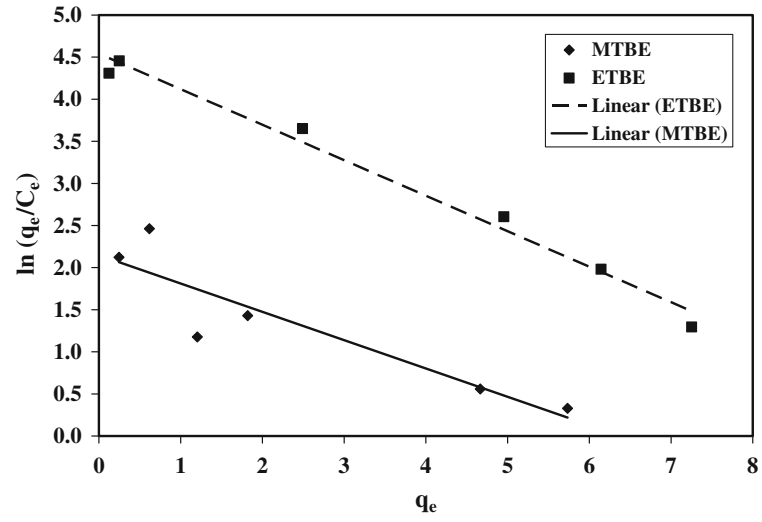

Fig. 5 Khan and Singh plots of $\ln \left(q_{\mathrm{e}} / C_{\mathrm{e}}\right)$ vs. $q_{\mathrm{e}}$ for the adsorption of MTBE and ETBE onto GAC

\section{Conclusions}

The equilibrium and kinetic parameters of MTBE and ETBE adsorption onto granular activated carbon were determined using nonlinear regression analysis. While Dubinin-Radushkevich isotherm described the equilibrium data better than the other isotherms tested for MTBE adsorption, similar values of $R^{2}$ and RMSE were obtained for Langmuir and Dubinin-Radushkevich isotherms for ETBE. The adsorption capacity of GAC was slightly higher for ETBE than that for MTBE, a result which is in agreement with those reported in the literature for the other GAC adsorbents. There were no significant differences between the performances of pseudo first-order and pseudo second-order kinetic models. Gibbs free-energy changes were negative for both the adsorption of MTBE and ETBE onto GAC. Although promising results were obtained for the single solute (i.e., MTBE

Table 3 Adsorption kinetic parameters

\begin{tabular}{|c|c|c|c|c|c|c|c|c|c|}
\hline \multirow[t]{2}{*}{$C_{0}(\mathrm{mg} / \mathrm{L})$} & \multirow[t]{2}{*}{$q_{\mathrm{e}}($ Exp.; mg/g) } & \multicolumn{4}{|c|}{ Pseudo first-order } & \multicolumn{4}{|c|}{ Pseudo second-order } \\
\hline & & $q_{\mathrm{e}}(\mathrm{mg} / \mathrm{g})$ & $k_{1}\left(\mathrm{~h}^{-1}\right)$ & $R^{2}$ & RMSE & $q_{\mathrm{e}}(\mathrm{mg} / \mathrm{g})$ & $k_{2}(\mathrm{~g} / \mathrm{mg} \mathrm{h})$ & $R^{2}$ & RMSE \\
\hline \multicolumn{10}{|l|}{ MTBE } \\
\hline 2 & 0.246 & 0.248 & 0.266 & 0.987 & 0.009 & 0.275 & 1.418 & 0.962 & 0.016 \\
\hline 5 & 0.618 & 0.599 & 0.604 & 0.989 & 0.019 & 0.620 & 2.532 & 0.991 & 0.018 \\
\hline 15 & 1.820 & 1.730 & 0.282 & 0.956 & 0.121 & 1.926 & 0.207 & 0.945 & 0.135 \\
\hline \multicolumn{10}{|l|}{ ETBE } \\
\hline 2 & 0.249 & 0.244 & 0.283 & 0.965 & 0.015 & 0.268 & 1.652 & 0.977 & 0.012 \\
\hline 5 & 0.612 & 0.621 & 0.138 & 0.915 & 0.061 & 0.720 & 0.257 & 0.907 & 0.063 \\
\hline 15 & 1.859 & 2.737 & 0.026 & 0.944 & 0.174 & 4.485 & 0.004 & 0.941 & 0.178 \\
\hline
\end{tabular}


or ETBE) adsorption capacity of NORIT GAC 1240, competitive effects of other gasoline components like BTEX or natural organic matter, and the performance of adsorbent under continuous operation should be investigated before the application of this adsorbent for the remediation of oxygenate-contaminated water.

Acknowledgments This study was supported in part by the Technical and Scientific Research Council of Turkey (MISAG-269) and the Izmir Institute of Technology (IZTECH) Research Fund (2004-IYTE 16). We would like to thank Izmir Regional Institute of Hygiene, IZTECH Environmental Research Center, and IZTECH Center for Material Research for their technical assistance.

\section{References}

Achten, C., Kolb, A., \& Puttmann, W. (2002). Occurrence of methyl tert-butyl ether (MTBE) in riverbank filtered water and drinking water produced by riverbank filtration. 2 . Environmental Science \& Technology, 36(17), 3662-3670.

Anderson, M. A. (2000). Removal of MTBE and other organic contaminants from water by sorption to high silica zeolites. Environmental Science \& Technology, 34(4), 725-727.

Annesini, M. C., Gironi, F., \& Monticelli, B. (2000). Removal of oxygenated pollutants from wastewater by polymeric resins: data on adsorption equilibrium and kinetics in fixed beds. Water Research, 34(11), 2989-2996.

API (American Petroleum Institute) (2000). Strategies for characterizing subsurface releases of gasoline containing MTBE. Publication No: API 4699.

Bi, E., Haderlein, S. B., \& Schmidt, T. C. (2005). Sorption of tert-butyl ether (MTBE) and tert-butyl alcohol (TBA) to synthetic resins. Water Research, 39, 4164-4176.

Centi, G., Grande, A., \& Perathoner, S. (2002). Catalytic conversion of MTBE to biodegradable chemicals in contaminated water. Catalysis Today, 75, 69-76.

Church, C. D., Isabelle, L. M., Pankow, J. F., Rose, D. L., et al. (1997). Method for determination of methyl tert-butyl ether and its degradation products in water. Environmental Science \& Technology, 31(12), 3723-3726.

Davis, S. W., \& Powers, S. E. (2000). Alternative sorbents for removing MTBE from gasoline-contaminated ground water. Journal of Environmental Engineering, 126(4), 354-360.

Dewsbury, P., Thornton, S. F., \& Lerner, D. N. (2003). Improved analysis of MTBE, TAME, and TBA in petroleum fuel-contaminated groundwater by SPME using deuterated internal standards with GC-MS. Environmental Science \& Technology, 37(7), 1392-1397.

EC (European Communities) (2002). European Union Risk Assessment Report-Tert-Butyl Methyl Ether.

Erdem-Senatalar, A., Bergendahl, J. A., Giaya, A., \& Thompson, R. W. (2004). Adsorption of methyl tertiary butyl ether on hydrophobic molecular sieves. Environmental Engineering Science, 21(6), 722-729.
Gimeno, O., Plucinski, P., Kolaczkowski, S. T., Rivas, F. J., et al. (2003). Removal of the herbicide MCPA by commercial activated carbons: Equilibrium, kinetics, and reversibility. Industrial and Engineering Chemistry Reseasrch, 42, 1076-1086.

Gunay, A., Arslankaya, E., \& Tosun, I. (2007). Lead removal from aqueous solution by natural and pretreated clinoptilolite: adsorption equilibrium and kinetics. Journal of Hazardous Materials, 146, 362-371.

Hong, S., Duttweiler, C. M., \& Lemley, A. T. (1999). Analysis of methyl tert-butyl ether and its degradation products by direct aqueous injection onto gas chromatography with mass spectrometry or flame ionization detection systems. Journal of Chromatography A, 857, 205-216.

Hung, H. W., \& Lin, T. F. (2006). Adsorption of MTBE from contaminated water by carbonaceous resins and mordenite zeolite. Journal of Hazardous Materials, B135, 210-217.

Li, L., Quinlivan, P. A., \& Knappe, D. R. U. (2002). Effects of activated carbon surface chemistry and pore structure on the adsorption of organic contaminants from aqueous solution. Carbon, 40, 2085-2100.

Li, S., Tuan, V. A., Noble, R. D., \& Falconer, J. L. (2003). MTBE adsorption on all-silica $\beta$ zeolite. Environmental Science \& Technology, 37(17), 4007-4010.

Lin, S. H., Wang, C. S., \& Chang, C. H. (2002). Removal of methyl tert-butyl ether from contaminated water by macroreticular resin. Ind. Eng. Chem. Res., 41, 41164121.

Lin, Z., Wilson, J. T., \& Fine, D. D. (2003). Avoiding hydrolysis of fuel ether oxygenates during static headspace analysis. Environmental Science \& Technology, 37(21), 4994-5000.

Milonjic, S. K. (2007). A consideration of the correct calculation of thermodynamic parameters of adsorption. Journal of the Serbian Chemical Society, 72(12), 13631367.

Piazza, F., Barbieri, A., Violante, F. S., \& Roda, A. (2001). A rapid and sensitive method for methyl tert-butyl ether analysis in water samples by use of solid phase microextraction and gas chromatography-mass spectrometry. Chemosphere, 44, 539-544.

Quinlivan, P. A., Li, L., \& Knappe, D. R. U. (2005). Effects of activated carbon characteristics on the simultaneous adsorption of aqueous organic micropollutants and natural organic matter. Water Research, 39, 1663-1673.

Rosell, M., Lacorte, S., Ginebreda, A., \& Barcelo, D. (2003). Simultaneous determination of methyl tert-butyl ether and its degradation products, other gasoline oxygenates and benzene, toluene, ethylbenzene and xylenes in Catalonian groundwater by purge-and-trap-gas chromatography-mass spectrometry. Journal of Chromatography A, 995, 171-184.

Schirmer, M., Effenberger, M., \& Weiss, H. (2002). The impact of the gasoline additive methyl tertiary-butyl ether (MTBE) on groundwater: a German perspective. In S. F. Thornton \& E. Oswald (Eds.), Groundwater quality: Natural and enhanced restoration of groundwater pollution (pp 567-570). Wallingford: IAHS Publication.

Shih, T. C., Wangpaichitr, M., \& Suffet, M. (2003). Evaluation of granular activated carbon technology for the removal of 
methyl tertiary butyl ether (MTBE) from drinking water. Water Research, 37, 375-385.

Steffan, R. J., McClay, K., Vainberg, S., Condee, C. W., et al. (1997). Biodegradation of the gasoline oxygenates methyl tert-butyl ether, ethyl tert-butyl ether, and tertamyl methyl ether by propane-oxidizing bacteria. Applied and Environmental Microbiology, 63(11), 4216-4222.

Sutherland, J., Adams, C., \& Kekobad, J. (2004). Treatment of MTBE by air stripping, carbon adsorption, and advanced oxidation: technical and economic comparison for five groundwaters. Water Research, 38, 193-205.

Sutherland, J., Adams, C., \& Kekobad, J. (2005). Treatability of alternative fuel oxygenates using advanced oxidation, air stripping, and carbon adsorption. Journal of Environmental Engineering, 131(4), 623-631.

Urkiaga, A., Bolano, N., \& De Las Fuentes, L. (2002). Removal of micropollutants in aqueous streams by organophilic pervaporation. Desalination, 149, 55-60.

US EPA (Environmental Protection Agency) (1997). Drinking water advisory-consumer acceptability advice and health effects analysis on methyl tertiary-butyl ether (MTBE). EPA-822-F-97-009.
US EPA (Environmental Protection Agency) (2000). Methyl Tertiary Butyl Ether (MTBE): Advance notice of intent to initiate rulemaking under the Toxic Substances Control Act to eliminate or limit the use of MTBE as a fuel additive in gasoline; Advance Notice of Proposed Rulemaking. Federal Register, 65(N 58), 16093-16109.

USGS (U.S. Geological Survey), U.S. Department of the Interior (2001). MTBE and other volatile organic compounds-New findings and implications on the quality of source waters used for drinking-water supplies. Report FS-105-01.

Wilhelm, M. J., Adams, V. D., Curtis, J. G., \& Middlebrooks, E. J. (2002). Carbon adsorption and air-stripping removal of MTBE from river water. Journal of Environmental Engineering, 128(9), 813-823.

Yu, L., Adams, C., \& Ludlow, D. (2005). Adsorption isotherms for methyl tert-butyl ether and other fuel oxygenates on two bituminous-coal activated carbons. Journal of Environmental Engineering, 131(6), 983-987.

Zwank, L., Schmidt, T. C., Haderlein, S. B., \& Berg, M. (2002). Simultaneous detection of fuel oxygenates and BTEX using direct aqueous injection gas chromatography mass spectrometry (DAI-GC/MS). Environmental Science \& Technology, 36(9), 2054-2059. 